\title{
Análise da Pegada Ecológica no Campus de Tupã da Universidade Estadual Paulista ${ }^{1}$
}

\section{Ecological Footprint Analysis in the Tupã Campus of the Universidade Estadual Paulista}

Análisis de la Huella Ecológica en el Campus de Tupã de la Universidade Estadual Paulista

Luana Ferreira Pires ${ }^{2}$ Angélica Gois Morales ${ }^{3}$ Ricardo Cesar Gonçalves Sant'Ana ${ }^{4}$

${ }^{1}$ Pesquisa financiada pela Fundação de Amparo à Pesquisa do Estado de São Paulo (FAPESP).

${ }^{2}$ Graduada em Administração e mestranda do Programa de Pósgraduação em Agronegócio e Desenvolvimento, pela Faculdade de Ciências e Engenharia da Universidade Estadual Paulista "Júlio de Mesquita Filho" (UNESP). Participante do Grupo de Pesquisa em Gestão e Educação Ambiental (PGEA), da Rede de Educação Ambiental da Alta Paulista (REAP) e membro da Comissão de Ética Ambiental da Faculdade de Ciências e Engenharia da UNESP. E-mail: Iuanaf.p@hotmail.com

${ }^{3}$ Graduada em Ciências Biológicas UNESP, mestre em Educação Ambiental pela Fundação Universidade Federal do Rio Grande e doutora em Meio

Ambiente e Desenvolvimento pela Universidade Federal do Paraná (UFPR). Professora no curso de Administração e no Programa de PósGraduação em Agronegócio e Desenvolvimento (PGAD) da UNESP. E-mail: angelica@tupa.unesp.br

${ }^{4}$ Graduado em Matemática e Pedagogia, mestre e doutor em Ciência da Informação pela UNESP. Professor no curso de Administração e no Programa de Pós-Graduação em Ciência da Informação da UNESP. E-mail: ricardosantana@tupa.unesp.br 
Resumo: O objetivo geral desta pesquisa foi analisar o impacto ambiental exercido pelas atividades no Campus de Tupã da Universidade Estadual Paulista "Júlio de Mesquita Filho" (UNESP), a partir do cálculo da Pegada Ecológica. A metodologia envolveu estudo de caso, abordagem mista e levantamento de dados primários e secundários, com aplicação de questionários semiestruturados aos discentes, docentes e técnicos administrativos do Campus, considerando um período de 12 meses. Para o cálculo da Pegada Ecológica, foram admitidas as mesmas equações de uma pesquisa realizada Campus de São Carlos da Universidade de São Paulo (USP), permitindo a comparação dos resultados. Esta pesquisa contribui para conhecimento das responsabilidades de cada um e da própria instituição mediante seu impacto ambiental, bem como pode proporcionar informações para possíveis atitudes mais sustentáveis na gestão e no comportamento coletivo e individual no Campus de Tupã.

Palavras-chave: impacto ambiental; indicador de sustentabilidade; padrão de consumo.

\begin{abstract}
The general purpose of this research is to analyze the environmental impact exercised for activities at Universidade Estadual Paulista "Júlio de Mesquita Filho" (UNESP), Campus of Tupã, from the calculation of the Ecological Footprint. The methodology involved case study, the mixed approach and collection of primary and secondary data with application of semistructured questionnaires to students, professors and administrative technicians, considering 12 months. For the calculation of Ecological Footprint were admitted the same equations of a research conducted at Campus of São Carlos, Universidade de São Paulo (USP), allowing a comparison of results. This research contributes for knowledge of responsibilities of each other and private institution through its environmental impact, as well as can provides information for possible attitudes more sustainable in management and collective behavior and individual at Tupã Campus.
\end{abstract}

Key words: environmental impact; sustainability indicator; consumption pattern.

Resumen: El objetivo de esta investigación fue analizar el impacto ambiental ejercido por las actividades en el Campus de Tupã de la Universidade Estadual Paulista "Júlio de Mesquita Filho" (UNESP), a partir del cálculo de la Huella Ecológica. La metodología incluyó el estudio de caso, el enfoque mixto y relevamiento de los datos primarios y secundarios, con aplicación de cuestionarios semi-estructurados a los estudiantes, profesores y técnicos administrativos del Campus, considerando un período de 12 meses. Para calcular la huella ecológica se admitieron las mismas ecuaciones de una encuesta realizada en el Campus de São Carlos, Universidade de São Paulo (USP), lo que permite la comparación de resultados. Esta investigación contribuye al conocimiento de las responsabilidades de cada uno y de la propia institución mediante su impacto ambiental, y puede proporcionar información para posibles actitudes más sostenibles en la gestión y el comportamiento colectivo e individual en el Campus de Tupã.

Palabras clave: impacto ambiental, indicadores de sostenibilidad, patrón de consumo. 


\section{INTRODUÇÃO}

O propósito de integrar sustentabilidade e desenvolvimento econômico tornou-se foco desde os primeiros eventos socioambientais, e cada vez mais debates nessa temática sinalizam a necessidade de repensar o uso dos recursos naturais nos sistemas econômicos e avaliar os prejuízos para o ambiente (AMARAL et al., 2013).

Dessa forma, com a finalidade de quantificar a sustentabilidade ambiental, muitos instrumentos quantitativos e qualitativos foram desenvolvidos, destacando-se os indicadores de sustentabilidade, que permitem verificar o cenário atual de um ambiente, podendo evidenciar fragilidades não identificadas anteriormente (QUIROGA, 2001). Como um desses instrumentos, destaca-se a Pegada Ecológica (PE), que vem sendo aplicada em vários segmentos da sociedade, como em universidades, conforme ressalta Amaral et al. (2013).

Portanto, a exemplos de pesquisas realizadas na Universidade de Santiago de Compostela (USC), na Espanha, e no Campus de São Carlos da Universidade de São Paulo, este estudo teve como objetivo geral analisar o impacto ambiental exercido pelas atividades no Campus de Tupã da Universidade Estadual Paulista "Júlio de Mesquita Filho" (UNESP), a partir do cálculo da Pegada Ecológica (PE).

\section{INDICADORES DE SUSTENTABILIDADE}

O discurso oficial do desenvolvimento sustentável está marcado por um contexto politicamente pragmático, dando ênfase maior nas dimensões econômicas e tecnológicas da sustentabilidade, articulando-se mais à lógica do mercado (MORALES, 2012). No entanto, à medida que esse conceito é cada vez mais apropriado pelas instituições, Sebastião (2010) chama a atenção para a necessidade de medir o desempenho das economias por meio de novas concepções de indicadores, para além do Produto Interno Bruto (PIB), que não abrange ativos da natureza e capital social e intelectual da população, 
com o propósito de operacionalizar o desenvolvimento sustentável percorrendo na prática o caminho teórico para a sustentabilidade.

A partir de meados da década de 80, iniciaram-se, no Canadá e em alguns países europeus, os estudos acerca dos indicadores de sustentabilidade, com gênese na economia e na ecologia, a fim de acompanhar continuamente a (in)sustentabilidade do padrão de crescimento socialmente adotado (QUIROGA, 2001).

Os indicadores de sustentabilidade objetivam agregar e quantificar de forma simplificada as informações de fenômenos complexos a fim de destacar sua relevância e facilitar o processo de comunicação. Ele emerge dos valores de seus idealizadores e também cria valores (BELLEN, 2006; AMARAL et al., 2013).

Conforme Sebastião (2010), os indicadores podem ser analisados isoladamente ou combinados entre si, permitindo conhecer as condições de um sistema e monitorar seu progresso em direção ao alcance de uma meta ou, ainda, identificar tendências e fenômenos não observados de imediato. Sendo assim, aqueles são importantes ferramentas de respaldo para a tomada de decisão e para a formulação de políticas públicas em todos os níveis, sendo uma das principais características quando comparados com outros tipos de informação.

Quiroga (2001) afirma que países como Canadá, Nova Zelândia e Suécia estão trabalhando de maneira autônoma e proativa no desenvolvimento de indicadores correspondentes à dimensão ambiental da sustentabilidade. Na América Latina, as instituições públicas têm assumido a produção dessas ferramentas em menor proporção e de forma morosa e descontínua, enfrentando desafios políticos e técnicos.

Destacam-se assim México, Chile, Colômbia, Costa Rica e Brasil, sendo que, neste último, a primeira experiência com indicadores de sustentabilidade ocorreu em 2004, promovida pelo Instituto Brasileiro de Geografia e Estatística (IBGE) ao inserir no relatório "Indicadores de desenvolvimento sustentável no Brasil". 
Barros e Kieling (2015) afirmam ser atribuída aos indicadores sustentabilidade a incumbência de abranger holisticamente a inter-relação das variáveis ambiental, social e econômica, de forma que categorizá-los desqualifica-os enquanto indicadores de sustentabilidade em si mesmos. Nessas circunstâncias, para Bellen (2006), eles dispõem de uma representatividade no interior do enquadramento do desenvolvimento sustentável.

Na dimensão ambiental, com o propósito de mensurar a sustentabilidade com ênfase na relação de demanda e oferta de recursos naturais, um estudo comparativo entre os métodos de avaliação internacionalmente conhecidos mostrou que, de um grupo de 24 indicadores ambientais, as três metodologias mais apontadas foram o Painel de Indicadores de Sustentabilidade ("Dashboard of Sustainability"), o Barômetro de Sustentabilidade ("Barometer of Sustainability") e o Método da Pegada Ecológica ("Ecological Footprint Method") (BELLEN, 2006).

A Pegada Ecológica (PE) tem obtido grande aceitação de diversos autores (NESS et al., 2007; TURNER et al., 2007; AMARAL et al., 2013) e organizações por configurar uma metodologia que resulta de forma clara e objetiva as pressões exercidas pelas atividades de manutenção da vida humana sobre meio ambiente, e devido ao seu potencial político-pedagógico (AMARAL et al., 2013).

\subsection{Pegada Ecológica}

Baseados na concepção de Capacidade de Carga $^{1}$, conceito e metodologia de cálculo da PE foram desenvolvidos no início dos anos de 1990 por Willian Rees e seu aluno de doutorado, Mathis Wackernagel, na University of British Columbia, Canadá. A publicação do livro "Our Ecological Footprint", obra desses autores, inaugurou o

\footnotetext{
${ }^{1}$ A biocapacidade representa a quantidade de área bioprodutiva, a qual os ecossistemas são capazes de produzir para a geração de materiais biológicos, necessários à manutenção humana, e absorção de resíduos (WACKERNAGEL; REES, 1996).
} 
empenho em consolidar o método como um instrumento de comunicação, medição e orientação para populações sustentáveis (BARROS; KIELING, 2015).

No contexto universitário, o apanhamento realizado por OlallaTárraga (2003) revela as universidades norte-americanas e de países anglo-saxônicos como as pioneiras na aplicação do cálculo da PE, utilizando, para tanto, métodos particulares. Outros exemplos são a Universidade de Redlands, na Califórnia, e Universidade do Texas. A Austrália e a Espanha também registraram iniciativas, destacando-se a Universidade Autônoma de Madrid, Universidade Politécnica de Catalunha e Universidade de Santiago de Compostela, que teve seu método de mensuração da Pegada Ecológica reproduzido no Brasil pelo Campus de São Carlos da USP.

A PE, hoje coordenada pela Global Footprint Network em conjunto com suas 50 organizações parceiras, representa a pressão exercida na biosfera, definida, segundo seus idealizadores, como uma ferramenta para estimar o consumo de recursos naturais e assimilação de resíduos gerados por uma determinada população humana, em termos de área de terra bioprodutiva seja qual for sua localização (WACKERNAGEL; REES, 1996).

Os principais objetivos da PE, conforme Barros e Kieling (2015) são: fundamentar a tomada de decisão e incentivar a edificação e o suporte da consciência social mediante os impactos negativos recorrentes sobre o meio ambiente, gerados a partir da utilização descomedida dos recursos ambientais e do consumismo. $O$ indicador busca ressaltar a responsabilidade de cada país na promoção de um desenvolvimento sustentável, isentando de prejuízos as próximas gerações.

Dados da World Wide Fund for Nature (WWF, 2007), em português Fundo Mundial para a Natureza, indicam que uma PE média per capita corresponde a 2,7 hectares globais, enquanto a biocapacidade é de 1,8 hectare global per capita, isso significa que a população mundial 
requer 1,5 planeta para sustentar seu padrão de consumo. No Brasil, a PE média equivale a 2,9 hectares globais per capita, valor apenas 0,2 hectare global per capita abaixo da média mundial de consumo. Ademais, foram publicados pela WWF os resultados da PE de Campo Grande, MS, e do município e estado de São Paulo, equivalentes a 3,14 hectares globais por pessoa, 4,38 hectares globais por pessoa e 3,52 hectares globais por pessoa, respectivamente.

Rodríguez, Iglesias e Álvarez (2008) apresentam os resultados da PE de regiões como os Estados Unidos (10 ha/pessoa/ano), Espanha (5 ha/pessoa/ano), Europa Ocidental (5 ha/pessoa/ano), África (1 ha/pessoa/ano) e América Latina (2 ha/pessoa/ano), o que deixa claro que há países que impactam muito mais que outros.

Para quantificar os recursos naturais utilizados na manutenção do padrão de consumo de uma população, a PE abrange elementos como habitação, bens domésticos, vestuário, transporte, alimentação, atividades de lazer, produtos adquiridos, dentre outros. Eles integram as cinco classes de consumo estabelecidas no método, para as quais é estimada a área bioprodutiva de terra necessária para produção do que é consumido e absorção dos resíduos gerados, a saber:

1. Alimentação: de origem animal e vegetal.

2. Habitação: áreas construídas.

3. Energia.

4. Bens e serviços: papel, roupas, bancos, aeroportos e outros.

5. Transporte.

Essas categorias podem ser reduzidas adequando-se à disponibilidade de dados e grau de exatidão necessário no cálculo, e de fatores variáveis em cada estudo (WWF, 2007).

A partir da $\mathrm{PE}$, é possível identificar as áreas mais vulneráveis e mais impactadas pelos seres humanos, permitindo trabalhar com ênfase nesses territórios a fim de corrigir deficiências e evitar a intensificação delas. Ademais, segundo Wackernagel e Rees (1996), a apli- 
cação do cálculo em séries temporais pode evidenciar se a tendência dos padrões de consumo vigentes é orientada ao overshoot ou a uma condição de superávit ecológico e produção de reserva ecológica.

Numa escala macro, como em países e comunidades, os resultados da PE podem direcionar a melhorias em processos produtivos, tecnologias adotadas, transportes e comercialização. Realizar mudanças nesses cenários implica custos e impacta também nas relações em regiões emergentes e desenvolvidas. Assim, o indicador pode conduzir a reformas estruturais nos sistemas, em direção à sustentabilidade (NEVES, 2013).

\section{METODOLOGIA}

Na sequência estão detalhados os elementos característicos do método adotado nesta pesquisa.

\subsection{Caracterização do cenário de estudo}

A Universidade Estadual Paulista "Júlio de Mesquita Filho", criada em 1976, hoje compreende 34 faculdades e institutos distribuídos em 24 cidades do estado de São Paulo e uma comunidade universitária de mais de 61 mil indivíduos, incluindo os corpos discente, docente e de servidores (UNESP, 2015).

Por iniciativa do Conselho de Reitores das Universidades Estaduais de São Paulo (CRUESP), em 2002, com apoio do Governo do Estado, as três universidades públicas do Estado de São Paulo iniciaram pesquisas com a finalidade de contribuir com as demandas sociais por meio da ampliação de vagas (CRUESP, 2005).

Nesse encaminhamento, no âmbito da UNESP, constituiu-se uma equipe de especialistas que atuaram na identificação de regiões e/ou microrregiões não atendidas pelo ensino superior público em decorrência de particularidades como geografia e condição socioeconômica 
social. Para acolher os novos cursos, o estudo indicou os municípios de Dracena, Itapeva, Ourinhos, Registro, Rosana, Sorocaba/Iperó e Tupã (CRUESP, 2005).

A pesquisa deu origem ao "Programa UNESP para Expansão de Vagas no Ensino Superior Público do Estado de São Paulo", pautado no convênio estabelecido entre Governo do Estado, UNESP e Prefeitura Municipal, promoveu o estabelecimento de sete novos campi, um deles na cidade de Tupã, em 2003, que inicialmente ofereceu 40 vagas para o curso de graduação em Administração de Empresas e Agronegócios. Três anos após a abertura, o curso passou a ser chamado Administração e a oferecer mais 40 vagas, destinadas ao período noturno a fim de atender a crescente demanda (CRUESP, 2005).

Atualmente, disposto em uma área de cerca de 80 mil metros quadrados, além das 80 vagas para o curso de Administração, o campus oferece 40 vagas para a graduação em Engenharia de Biossistemas, bem como curso de pós-graduação Lato Sensu em Gestão do Agronegócio e o Strictu Sensu, Mestrado Acadêmico em Agronegócio e Desenvolvimento (UNESP, 2012).

No ano de 2015, quando foi realizada a pesquisa, segundo dados fornecidos pela Seção Técnica de Graduação e Pós-Graduação, a população do campus totalizava 532 indivíduos dos quais 363 eram discentes de Administração, 74 eram discentes de Engenharia de Biossistemas, 32 eram discentes da pós-graduação, 19 eram docentes de Administração, 11 eram docentes de Engenharia de Biossistemas e 33 eram técnicos administrativos.

Ressalta-se que a nomenclatura "Unidade Diferenciada de Tupã" foi substituída em 2006 por "Campus Experimental de Tupã" e, em 2015, após o período de análises e trâmites em comissões da reitoria e órgão colegiados, o campus foi consolidado Unidade Universitária e oficializando-se a denominação "Faculdade de Ciências e Engenharia (FCE)". 


\subsection{Etapas para o cálculo da Pegada Ecológica}

Este estudo de caso compreendeu as abordagens quantitativa e qualitativa, e foi amparado por pesquisa bibliográfica e pesquisa de campo. Para mensurar a Pegada Ecológica do Campus de Tupã foi considerado um período de 12 meses, de outubro de 2014 a setembro de 2015.

Foram eleitos cinco parâmetros para o cálculo da PE, consoante ao estudo de Amaral (2010): consumo de água, consumo de energia elétrica, consumo de papel, áreas construídas e transporte. A coleta de dados dos parâmetros de consumo associados à instituição de ensino ocorreu por meio do contato com os responsáveis pela Área de Serviços/Comunicações e pela Área de Compras / Almoxarifado / Patrimônio. Os dados associados aos discentes, docentes e técnicos administrativos foram coletados por meio de questionários semiestruturados, específicos para cada uma dessas três categorias de sujeitos, obtendo-se cerca de $34,96 \%$ de devolução da população total do campus que corresponde a 532 sujeitos (Quadro 1).

\begin{tabular}{|l|c|c|c|}
\hline \multicolumn{1}{|c|}{ Categoria } & População & Respondentes & $\begin{array}{c}\text { Porcentagem } \\
\text { Correspondente (\%) }\end{array}$ \\
\hline Discentes Administração & 363 & 110 & 30,30 \\
\hline $\begin{array}{l}\text { Discentes Engenharia de } \\
\text { Biossistemas }\end{array}$ & 74 & 18 & 24,32 \\
\hline Discentes Pós-Graduação & 32 & 15 & 42,86 \\
\hline Docentes Administração & 19 & 14 & 73,68 \\
\hline $\begin{array}{l}\text { Docentes Engenharia de } \\
\text { Biossistemas }\end{array}$ & 11 & 8 & 72,72 \\
\hline Técnicos Administrativos & 33 & 21 & 63,63 \\
\hline Total & $\mathbf{5 3 2}$ & $\mathbf{1 8 6}$ & $\mathbf{3 4 , 9 6}$ \\
\hline
\end{tabular}

Quadro 1 - Número de respondentes ao questionário da pesquisa por categoria e porcentagem correspondente do Campus de Tupã da UNESP Fonte: Elaborado pelos autores. 
Ressalta-se que foram utilizados os fatores de emissão para cada parâmetro de consumo, taxa de absorção de carbono fixada em $6,27 \mathrm{tCO}_{2} /$ ha/ano e equações consoante a metodologia aplicada por Amaral (2010). A seguir, estão descritas as etapas realizadas para a obtenção da Pegada Ecológica do Campus de Tupã.

\subsubsection{Etapa 1: Definição dos fatores de emissão}

Fator de emissão é como se designa a estimativa de emissão de Gases de Efeito Estufa, neste caso o dióxido de carbono, a partir da unidade de dados do recurso consumido. Para este estudo foram admitidos os fatores de emissão indicados no Quadro 2, conforme os parâmetros de consumo que serão trabalhados.

\begin{tabular}{|c|c|c|c|c|}
\hline \multirow{2}{*}{\multicolumn{2}{|c|}{ Água }} & $\begin{array}{l}\text { Fator de } \\
\text { emissão }\end{array}$ & Unidades & Fonte \\
\hline & & 0,50 & $\mathrm{kgCO} 2 / \mathrm{m}^{2}$ & $\begin{array}{l}\text { Governo Municipal de } \\
\text { Santiago de Compostela, } \\
\text { Espanha apud Projeto } \\
\text { Cálculo Pegada Ecológica } \\
\text { Universidade de Santiago } \\
\text { de Compostela (USC) }\end{array}$ \\
\hline \multicolumn{2}{|c|}{$\begin{array}{c}\text { Construção dos } \\
\text { edifícios }\end{array}$} & 520 & $\mathrm{kgCO} 2 / \mathrm{m}^{2}$ & $\begin{array}{c}\text { Informe MIES, } 1999 \text { apud } \\
\text { Projeto Cálculo Pegada } \\
\text { Ecológica (USC) }\end{array}$ \\
\hline \multicolumn{2}{|c|}{ Energia Elétrica } & 0,57 & $\begin{array}{l}\mathrm{kgCO} 2 / \\
\text { kWh }\end{array}$ & $\begin{array}{c}\text { Instituto Energético de } \\
\text { Galicia, } 2007 \text { apud Projeto } \\
\text { Cálculo Pegada Ecológica } \\
\text { (USC) }\end{array}$ \\
\hline \multirow{2}{*}{ Papel } & Reciclado & 0,61 & \multirow{2}{*}{$\begin{array}{c}\mathrm{kgCO} 2 / \mathrm{kg} \\
\text { papel }\end{array}$} & \multirow{2}{*}{$\begin{array}{c}\text { Projeto Cálculo Pegada } \\
\text { Ecológica (USC) }\end{array}$} \\
\hline & Virgem & 1,84 & & \\
\hline
\end{tabular}




\begin{tabular}{|l|c|c|c|c|}
\hline \multirow{4}{*}{$\begin{array}{l}\text { Trans- } \\
\text { porte }\end{array}$} & Moto & 0,7 & \multirow{4}{*}{} & \multirow{4}{*}{$\mathrm{kgCO} 2 / \mathrm{km}$} \\
\cline { 2 - 3 } & Ônibus & 0,4 & \\
\cline { 2 - 3 } & Avião & 0,11 & & \\
\cline { 2 - 3 } & Automóvel* & 0,05 a 0,20 & & \\
\hline
\end{tabular}

Quadro 2-Fatores de emissão do consumo de água, áreas construídas, consumo de energia elétrica, consumo de papel e transporte, segundo método utilizado por Amaral (2010)

* O fator de emissão para o meio de transporte automóvel pode variar de acordo com o nível de ocupação (1 ou 2 pessoas emitem 0,20 kgCO2/km; 3 pessoas emitem $0,10 \mathrm{kgCO} 2 / \mathrm{km} ; 4$ pessoas emitem $0,07 \mathrm{kgCO} 2 / \mathrm{km}$ e 5 pessoas emitem 0,05 kgCO2/km).

Fonte: Adaptado de Amaral (2010).

3.2.2 Etapa 2: Conversão do consumo em emissão de dióxido de carbono $\left(\mathrm{CO}_{2}\right)$

Fixados os fatores de emissão para cada item de consumo, o passo seguinte foi a conversão do consumo em emissão de dióxido de carbono $\left(\mathrm{CO}_{2}\right)$ a partir da Equação 1 .

Emissão $\left(\mathrm{KgCO}_{2}\right)=$ Consumo (unidade $) \times$ Fator de emissão $(\mathrm{KgCO} 2 /$ unidade $)$

Equação 1 - Conversão do consumo em emissão de Dióxido de Carbono (CO2)

Essa operação foi realizada para cada um dos cinco parâmetros de consumo selecionados para o estudo, sendo que o fator de emissão associado à construção dos edifícios considera o tempo de vida útil de um edifício de 50 anos, portanto, o valor final de $\mathrm{kgCO}_{2}$, obtido na Equação 1, foi dividido por 50, pois foi analisado o período de um ano, conforme o método adotado por Amaral (2010). 


\subsubsection{Etapa 3: Cálculo da Pegada Ecológica}

A obtenção da Pegada Ecológica, indicada pela Equação 2, envolve a divisão do resultado obtido na Equação 1, após sua conversão em tonelada, pela taxa de absorção de carbono, fixada em 6,27 tCO2/ ha/ano por floresta plantada. Esse valor representa a capacidade de absorção de dióxido de carbono por floresta plantada, contudo o número estabelecido não considera as florestas consolidadas por caracterizarem estabilidade na absorção de $\mathrm{CO} 2$, portanto estão compreendidas as florestas a serem plantadas, consoante o método utilizado por Amaral (2010).

Pegada Ecológica (ha) = Emissão ( $\left.\mathrm{tCO}_{2}\right)$ / Taxa de absorção de carbono (tCO2/ ha/ano)

Equação 2 - Pegada Ecológica

Essa operação foi realizada para cada um dos cinco parâmetros de consumo selecionados para o estudo e, em seguida, para estimar a Pegada Ecológica total do Campus de Tupã da UNESP, foram somados os totais obtidos no cálculo da PE de cada um deles.

Finalmente, para fins comparativos, foi estimado o valor per capita do indicador a partir da aplicação da Equação 3, a qual consiste na divisão da Pegada Ecológica, obtida na Equação 2, pelo tamanho amostral correspondente à cada categoria de sujeito da pesquisa.

Pegada Ecológica per capita (ha) = Pegada Ecológica (ha) / Amostra

Equação 3 - Pegada Ecológica per capita

Essa operação foi realizada para os parâmetros de consumo indicados na apresentação dos resultados. Ressalta-se que, para o cálculo da Pegada Ecológica do Campus de Tupã da UNESP, foram somados os totais obtidos no cálculo da PE de todos os parâmetros 
de consumo e efetuada a divisão pela população estudada, o equivalente a 532 indivíduos.

\section{APRESENTAÇÃO DOS RESULTADOS}

Ressalta-se que não foram encontradas pesquisas mais recentes no Campus de São Carlos da USP, com a aplicação da metodologia da PE, sendo, portanto, o trabalho de Amaral (2010) referência para as comparações e discussões proposta nesta pesquisa.

O Quadro 3 apresenta a demanda de cada categoria de consumo em números absolutos, bem como a fonte de coleta de dados, considerando o período compreendido entre outubro de 2014 e setembro de 2015.

\begin{tabular}{|l|c|c|}
\hline $\begin{array}{l}\text { Parâmetro de } \\
\text { consumo }\end{array}$ & $\begin{array}{c}\text { Consumo } \\
\text { absoluto/ano }\end{array}$ & Fonte de dados \\
\hline Consumo de água & $2.706 \mathrm{~m}^{3}$ & $\begin{array}{c}\text { Área de Serviços / } \\
\text { Comunicações }\end{array}$ \\
\hline $\begin{array}{l}\text { Consumo de } \\
\text { energia elétrica }\end{array}$ & $258.558 \mathrm{kWh}$ & $\begin{array}{c}\text { Área de Serviços / } \\
\text { Comunicações }\end{array}$ \\
\hline \multirow{2}{*}{ Consumo de papel } & 280.500 folhas* & $\begin{array}{c}\text { Área de Compras / } \\
\text { Almoxarifado / Patrimônio }\end{array}$ \\
\cline { 2 - 4 } & $71.563 \mathrm{folhas} *$ & Questionário \\
\hline \multirow{2}{*}{ Áreas Construídas } & $6.567,99 \mathrm{~m}^{2}$ & $\begin{array}{c}\text { Área de Serviços / } \\
\text { Comunicações }\end{array}$ \\
\hline \multirow{2}{*}{ Transporte } & $76.271 \mathrm{~km}^{*}$ & $\begin{array}{c}\text { Área de Serviços / } \\
\text { Comunicações }\end{array}$ \\
\cline { 2 - 4 } & $622.368,83 \mathrm{~km}^{* *}$ & Questionário \\
\hline
\end{tabular}

Quadro 3 - Consumo absoluto anual e fonte de coleta de dados por parâmetro de consumo do Campus de Tupã da UNESP de outubro de 2014 a setembro de 2015

*Consumo associado à instituição de ensino.

**Consumo associado a docentes, discentes e técnicos administrativos.

Fonte: Elaborado pelos autores. 
As medições de consumo hídrico, até outubro de 2014, ocorriam apenas no âmbito dos prédios - prédio principal, prédio administrativo e biblioteca. A partir de novembro de 2014, a mensuração se iniciou também na área experimental, onde ocorrem os ensaios relacionados aos projetos desenvolvidos no campus, portanto seu consumo foi inferior comparado aos demais setores. Em janeiro de 2015, esse espaço recebeu também um ponto de energia elétrica.

O consumo de papel associado à instituição de ensino alude à quantidade utilizada do material no atendimento da demanda de docentes e técnicos administrativos. Esse papel é 100\% proveniente de fibra virgem, refletindo maior emissão de $\mathrm{CO}_{2}$ e, consequentemente, maior PE, além de o consumo ter sido aproximadamente quatro vezes maior que o de discentes e de docentes, nesse último caso quando o material é acessado por outros meios (71.563 folhas).

Isso acontece devido à licitação pela qual passam os materiais adquiridos pela instituição, processo em que as especificidades, tais como marca e tipo, não podem ser exigidas. A efetuação da compra ocorre em função do preço do produto, portanto a aquisição do papel de fibra virgem é recorrente por seu preço inferior em comparação ao papel reciclado. Os discentes também apontaram o preço como fator inibidor do uso de papel reciclado, o que justifica 65,7\% não terem utilizado papel reciclado no período abarcado pela pesquisa.

O consumo de papel adquirido via projetos financiados por agências externas, como FAPESP e CNPq, não é apurado pelo sistema da instituição, mas também é atribuído também ao corpo docente. Por meio dos questionários, observou-se irrisória ocorrência dessa prática, apenas dois professores da amostra indicaram obter pequenas quantidades do material mediante esse tipo de recurso, confirmado pelos dados do Quadro 4. 


\begin{tabular}{|l|c|c|c|}
\hline Categoria & População & $\begin{array}{c}\mathbf{C O}_{\mathbf{2}} \text { emitido } \\
\text { (t/ano) }\end{array}$ & $\begin{array}{c}\text { PE Total } \\
\text { (ha/ano) }\end{array}$ \\
\hline Discentes Graduação & 437 & 1,943 & 0,310 \\
\hline Discentes Pós-graduação & 32 & 0,164 & 0,026 \\
\hline Docentes & 30 & 0,007 & 0,001 \\
\hline Total & 499 & 2,114 & 0,337 \\
\hline
\end{tabular}

Quadro 4- $\mathrm{CO}_{2}$ emitido e Pegada Ecológica do consumo de papel do Campus de Tupã da UNESP de outubro de 2014 a setembro de 2015 Fonte: Elaborado pelos autores.

Salienta-se que, em relação aos docentes, os resultados apontados no Quadro 4 foram calculados, apenas, a partir da quantidade de papel adquirida por meio de recursos de agências externas, conforme os valores informados nos questionários. Portanto evidencia-se que, majoritariamente, o consumo de papel dessa categoria integra o consumo de papel associado à instituição.

Verificou-se que os discentes foram os que mais descartaram papel, até $50 \%$ foi rejeitado por mais da metade dos respondentes, em oposição aos 90,5\% de técnicos administrativos que rejeitaram até $25 \%$. Constatou-se que a destinação desse material é desconhecida por $41 \%$ dos inqueridos.

A prefeitura do município de Tupã dispõe do serviço de coleta seletiva, e, dessa forma, alguns respondentes mencionaram pressupor que todo lixo recolhido na instituição de ensino seja destinado à reciclagem. Por meio do contato com uma das servidoras responsável pela limpeza, essa suposição foi confirmada, entretanto, entre discentes, docentes e técnicos administrativos, há um desconhecimento do efetivo encaminhamento dado ao resíduo. Existem ainda documentos que não podem ser descartados no lixo comum, devendo ser destruídos.

Em toda a amostra, existiu a preocupação em reutilizar o papel, a categoria dos discentes foi a única a apresentar indivíduos que não 
reaproveitaram o material, entretanto a maior parte dos questionados respondeu adotar essa conduta, seja sempre ou às vezes.

O campus não detém um sistema de controle do consumo de papel por área, assim, a partir dos dados obtidos por meio das respostas da amostra, é possível afirmar que a maioria dos docentes utilizou de 20 a 200 folhas por mês, enquanto os técnicos administrativos, majoritariamente, fizeram uso mensal de até 100 folhas.

Os sujeitos da pesquisa estão continuamente expostos às condições que influenciam a utilização de papel. Os toners, igualmente adquiridos por licitação, ocasionalmente resultam numa impressão de baixa qualidade que é descartada e substituída por novas, aumentando o consumo e rejeito de papel. Ademais, áreas como a Coordenação de Curso e de prestação de suporte aos projetos de extensão e atividades similares, demandam muitos documentos, embora tenha sido alegada a redução do número de impressões para subvencionar essas ocupações.

Também afetam o consumo fatores como o formato de disponibilização dos materiais adicionais às aulas e de exigência para a entrega de trabalhos, predominantemente via arquivos virtuais, com o subsídio de ferramentas como Dropbox e Google Drive, contribuindo para a redução do uso e impactando também na demanda por serviços bibliotecários.

No que concerne às áreas construídas, destaca-se que, a princípio, conforme presumia a criação das Unidades Diferenciadas, coube à Prefeitura Municipal de Tupã a cessão do espaço físico para a instalação da unidade. Posteriormente, foram realizadas reformas e novas obras, como o Laboratório, sobre o qual se ressalta que está em processo de construção, motivo que justifica ainda não ser considerado posse da instituição, contudo integrou o cálculo da Pegada Ecológica.

A área total do campus equivale a $85.074,09 \mathrm{~m}^{2}$, de forma que a área construída, 6.567,99 $\mathrm{m}^{2}$, representa 7,72\% desse valor. 
Os cálculos acerca do parâmetro de consumo "Transporte", referentes aos veículos oficiais da instituição de ensino, apontaram para a maior utilização dos automóveis FIAT/Palio Weekend e GM/Meriva Premium, e caminhonete VW/Amarok, demandados especialmente para a locomoção de docentes e técnicos administrativos para fins de treinamento e convocação.

A PE total do transporte associado aos discentes, docentes e técnicos administrativos foi composta em cerca de 93,04\% pela demanda total de terra bioprodutiva dos graduandos, conforme mostram os dados extrapolados do Quadro 5.

\begin{tabular}{|l|c|c|c|}
\hline Categoria & População & $\begin{array}{c}\mathbf{C O}_{\mathbf{2}} \text { emitido } \\
\text { (t/ano) }\end{array}$ & $\begin{array}{c}\text { PE Total } \\
\text { (ha/ano) }\end{array}$ \\
\hline Discentes Graduação & 437 & 327,72 & 52,27 \\
\hline Discentes Pós-graduação & 32 & 4,51 & 0,72 \\
\hline Docentes & 30 & 11,30 & 1,80 \\
\hline Técnicos Administrativos & 33 & 8,75 & 1,40 \\
\hline Total & 532 & 352,28 & 56,18 \\
\hline
\end{tabular}

Quadro 5 - $\mathrm{CO}_{2}$ emitido e Pegada Ecológica do consumo de papel do Campus de Tupã de outubro de 2014 a setembro de 2015 Fonte: Elaborado pelos autores.

Embora a distância percorrida pelos discentes da pós-graduação por vezes tenha sido maior, considerando que parte deles residia em outros municípios, os graduandos deslocaram-se até o campus com maior frequência. Docentes e técnicos administrativos apresentaram totais de toneladas de $\mathrm{CO}_{2}$ e PE muito próximos, igualmente foram os resultados per capita.

Em todas as categorias, o automóvel foi o meio de transporte mais utilizado para a locomoção até o campus, seguido da moto. Docentes e técnicos administrativos foram os principais usuários do carro, percentuais correspondentes a 93\% e 70\% respectivamente, 
estando entre as justificativas para essa prática a distância entre a residência dos respondentes e a instituição de ensino.

O campus está localizado a 3,6 quilômetros da avenida principal e, em seu entorno, não são oferecidos muitos serviços, portanto, $31 \%$ dos respondentes domiciliavam-se na região central. Embora na cidade de Tupã seja disponibilizado transporte público, os horários e as rotas não atendem com eficiência as necessidades da população universitária, o que gera o aumento da utilização do automóvel e a baixa adesão ao ônibus, mais utilizado na locomoção de técnicos administrativos e discentes residentes em outros municípios.

Apesar de ter sido o automóvel o meio de transporte mais utilizado, 36\% dos sujeitos da amostra residem na região leste, principal zona em todas as categorias, à qual pertence o Campus de Tupã da UNESP, favorecendo o deslocamento caminhando ou pedalando que, segundo Amaral (2010), são respectivamente pertinentes a distâncias inferiores a 1,8 quilômetros e 6,8 quilômetros. Contudo essas alternativas tornam-se inapropriadas mediante a necessidade dos inqueridos de realizar outras atividades que antecedem o trajeto com destino à instituição, a geografia urbana e a inexistência de infraestrutura adequada no município.

Nessas circunstâncias o compartilhamento de automóvel coloca-se como uma possibilidade com vistas à redução do impacto ambiental negativo gerado pelo transporte, entretanto observa-se que essa prática não é recorrente.

A ocupação da capacidade máxima do automóvel correspondeu a $14 \%$ dos casos e ocorreu apenas entre os discentes. Docentes e técnicos administrativos estão representados majoritariamente nos $39 \%$ e $23 \%$ que, respectivamente, não compartilharam o veículo ou transportaram o motorista e apenas um acompanhante.

O Quadro 6 reúne os totais de emissão de $\mathrm{CO}_{2}$ e de PE por parâmetro de consumo, bem como a quantidade total de terra biopro- 
dutiva demandada pelo Campus de Tupã no período compreendido pelo estudo.

\begin{tabular}{|l|c|c|}
\hline Parâmetro de consumo & $\begin{array}{c}\mathbf{C O}_{\mathbf{2}} \text { emitido } \\
\text { (t/ano) }\end{array}$ & $\begin{array}{c}\text { PE Total } \\
\text { (ha/ano) }\end{array}$ \\
\hline Consumo de água & 1,35 & 0,22 \\
\hline Consumo de energia elétrica & 147,38 & 23,51 \\
\hline Consumo de papel & 4,52 & 0,72 \\
\hline Áreas construídas & 68,31 & 10,89 \\
\hline Transporte & 365,9 & 58,35 \\
\hline Total & $\mathbf{5 8 7 , 4 6}$ & $\mathbf{9 3 , 6 9}$ \\
\hline
\end{tabular}

Quadro 6 - Síntese das emissões de $\mathrm{CO}_{2}$ e da Pegada Ecológica do Campus de Tupã de outubro de 2014 a setembro de 2015 por parâmetro de consumo

Fonte: Elaborado pelos autores.

O transporte foi o parâmetro de consumo que mais contribuiu com o resultado final do indicador correspondendo a aproximadamente $62 \%$ do total, seguido de cerca de $25 \%$ do consumo de energia e $12 \%$ das áreas construídas.

\section{COMPARAÇÃO DOS DADOS ENTRE DA UNESP (CAMPUS TUPÃ) E DA USP (CAMPUS SÃO CARLOS)}

Segundo elucida o Quadro 7, o parâmetro mais representativo na composição da PE total do Campus de São Carlos foi o consumo de energia elétrica. Amaral (2010) e Amaral et al. (2013) atribuem o alto valor do indicador ao fator de emissão aplicado, baseado na matriz energética espanhola. Em seguida destaca-se a PE das áreas construídas. 


\begin{tabular}{|l|c|c|}
\hline Parâmetro de consumo & $\begin{array}{c}\text { Campus Tupã - } \\
\text { UNESP } \\
\text { PE (ha/ano) }\end{array}$ & $\begin{array}{c}\text { Campus São Carlos } \\
\text { - USP } \\
\text { PE (ha/ano) }\end{array}$ \\
\hline Consumo de água & 0,22 & 12,88 \\
\hline Consumo de energia elétrica & 23,51 & $1.027,49$ \\
\hline Consumo de papel & 0,72 & 18,39 \\
\hline Áreas construídas & 10,89 & 288,17 \\
\hline Transporte & 58,35 & 197,34 \\
\hline Total & $\mathbf{9 3 , 6 9}$ & $\mathbf{1 . 5 4 4 , 2 7}$ \\
\hline População & 532 & 8.023 \\
\hline Total per capita & $\mathbf{0 , 1 8}$ & $\mathbf{0 , 1 9}$ \\
\hline
\end{tabular}

Quadro 7 - Comparativo entre a Pegada Ecológica do Campus de Tupã da UNESP e do Campus de São Carlos da USP

Fonte: Elaborado pelos autores.

De acordo com Amaral (2010) e Amaral et al. (2013), a redução da $\mathrm{PE}$ relativa às áreas construídas requer planejamento para reformas e futuras construções, portanto configura-se em esforços com resultados obtidos em longo prazo. Partindo desse pressuposto, assim como no Campus de Tupã, o parâmetro transporte no Campus de São Carlos assume relevância na composição da PE e exige a adoção de medidas de mitigação.

Observa-se ainda que, embora no total a PE dos parâmetros de consumo foram distantes entre si, comparando as duas instituições, a PE per capita apresentou diferença de aproximadamente 0,01 hectare de terra bioprodutiva, tendo o Campus de São Carlos encerrado o ano de 2008 com 0,19 ha/pessoa/ano, e o Campus de Tupã, o período compreendido de outubro de 2014 a setembro de 2015, com 0,18 ha/pessoa/ano.

Vale discutir algumas diferenças tais qual o consumo de papel que, considerando a ascensão dos arquivos digitais, é possível que a PE desse parâmetro tenha reduzido no Campus de São Carlos dado 
o ano de 2008 como base do estudo de Amaral (2010). Da mesma forma, sobre as áreas construídas, deve-se ponderar que a unidade mencionada possui 18 programas de pós-graduação e 23 cursos de graduação com predominância das Ciências Exatas, que necessitam de infraestrutura que comporte laboratórios. Além disso, as áreas construídas são divididas em duas unidades de Campus, área esportiva, Centro de Recursos Hídricos e Ecologia Aplicada e Centro de Divulgação Científica e Cultural.

Por fim, constatou-se que a PE do Campus de Tupã superou a do Campus de São Carlos apenas no parâmetro de consumo "Transporte". Em valores absolutos, a PE do Campus da USP se sobrepôs em 28,3 hectares anuais, contudo, ponderando os valores por cada indivíduo da população das duas instituições de ensino, a PE do Campus da UNESP foi $3 \mathrm{~m}^{2}$ maior.

Dada a representatividade do parâmetro "transporte", colocam-se como medidas mitigadoras do impacto por ele causado o fomento da utilização de bicicleta e do compartilhamento de meios de transporte capazes de comportar mais de um indivíduo, especialmente o automóvel, já que os veículos de docentes e técnicos administrativos apresentaram os menores percentuais de nível de ocupação.

Acredita-se também que a universidade possa adotar estratégias de educação ambiental para repensar as formas de conduta em relação aos seus consumos, contribuindo com a participação ativa da comunidade para discutir com a realidade local. Portanto um grupo ou comissão que possa pensar como melhor administrar os impactos desses consumos e criar seus próprios indicadores é uma sugestão para mitigar possíveis problemas decorrentes de espaços novos que estão sendo criados no Campus de Tupã, como o prédio de laboratórios para o curso de Engenharia de Biossistemas. 


\section{CONSIDERAÇÕES FINAIS}

Para além das características intrínsecas de todo indicador, os indicadores de sustentabilidade são vias para a transição do conceito de desenvolvimento sustentável em práticas operacionais efetivas, promovendo a redução da distância entre a abstração conceitual e a tomada diária de decisões.

A ascensão da aplicação da metodologia da Pegada Ecológica, em particular no contexto universitário, evidencia, com poucos parâmetros de consumo, o impacto provocado pelo funcionamento de uma instituição de ensino e a dimensão da demanda por recursos naturais de um indivíduo.

Considera-se também que cada universidade tem sua particularidade, e a comparação do Campus de Tupã da UNESP com o de São Carlos da USP, embora com parâmetros de relação, salienta que esses dados utilizados do estudo com base em 2008 talvez não seja mais representativo da realidade atual. Ademais, a PE, enquanto indicador de estado, requer e respalda respostas em forma de criação de campanhas e regulamentos institucionais. Portanto este estudo que visou analisar o impacto sobre o meio ambiente exercido pelas atividades realizadas no Campus de Tupã da UNESP traz a mensuração dos parâmetros de consumo de água, papel, energia elétrica, transporte e áreas construídas, o que contribui para o conhecimento da pegada ecológica do próprio campus, bem como de cada indivíduo. Dessa forma, tal compreensão instiga pensar em formas de conduta que possam melhorar determinados consumos, e a educação ambiental torna-se um caminho interessante para essa reflexão, discussão e ação.

Por fim, também ressalta ser interessante a continuidade do estudo com vistas à produção de um banco de dados e organização de séries históricas que permitam comparar o progresso do campus na redução da Pegada Ecológica. 


\section{REFERÊNCIAS}

AMARAL, R. C. Análise da aplicabilidade da Pegada Ecológica em contextos universitários: estudo de caso no campus de São Carlos da Universidade de São Paulo. 2010. Monografia (Bacharelado em Engenharia Ambiental) Universidade de São Paulo, São Carlos, SP, 2010. Disponível em: <http://www. tcc.sc.usp.br/tce/disponiveis/18/180300/tce-15022011-145930/publico/ Amaral_Renata_Castiglioni.pdf >. Acesso em: 20 maio 2014.

AMARAL, R.; HERAS, D. B.; LEME, P. C. S.; MALHEIROS, T. F. Aplicabilidade da pegada ecológica em contextos universitários. In: PHILIPPI JÚNIOR, A.; MALHEIROS, T. F. (Org.). Indicadores de sustentabilidade e gestão ambiental. Barueri, SP: Manole, 2013. p. 495-522.

BARROS, M. V. A.; KIELING, A. C. Ecological footprint: approximate for a study on applicability of Industrial Industries Polo Manaus Free Zone-PIM (Brazil). Review of Research, v. 4, n. 6, p. 1-6, mar. 2015. Disponível em: <http://ror. isrj.org/UploadedData/1423.pdf>. Acesso em: 13 set. 2015.

BELLEN, H. M. V. Indicadores de sustentabilidade: uma análise comparativa. Rio de Janeiro: FGV, 2006.

CONSELHO DE REITORES DAS UNIVERSIDADES ESTADUAIS PAULISTAS (CRUESP). Ofício n. 22/2005 dirigido ao Governador do Estado de São Paulo, 2005. Disponível em: <http://www.adusp.org.br/files/database/2014/ cruesp/of_cruesp_gov.pdf>. Acesso em: 17 ago. 2014.

MORALES, A. G. A formação do profissional educador ambiental: reflexões, possibilidades e constatações. Ponta Grossa, PR: UEPG, 2012.

NESS, B.; URBEL-PIIRSALU, E.; ANDERBERG, S.; OLSSON, L. Categorising tools for sustainability assessment. Ecological Economics, v. 60, n. 3, p. 498-508, jan. 2007. Disponível em: <http://ac.els-cdn.com/S0921800906003636/1s2.0-S0921800906003636-main.pdf?_tid=9bd67306-8e5c-11e6-bf5a00000aab0f02\&acdnat=1476044088_242aa0d19cf209a8f5a23f12d0 eb9737>. Acesso em: 7 ago. 2015.

NEVES, M. L. H. Desenvolvimento, economia e ecologia: um balanço. 2013. Monografia (Bacharelado em Ciências Econômicas) - Universidade Federal de Santa Catarina, Florianópolis, 2013. Disponível em: <http://cnm.ufsc. br/files/2013/09/Monografia-da-Maria-Luiza-Neves.pdf>. Acesso em: 6 out. 2015. 
OLALLA-TÁRRAGA, M. A. Indicadores de sostenibilidad y huella ecológica: aplicación a la UAM. Proyeto de Fin de Carrera de la Licienciatura de Ciencias Ambientales, 2003. Disponível em: <http://www.uam.es/servicios/ ecocampus/especifica/descargas/investigacion/Resumen_PFC_Indicadores. pdf>. Acesso em: 23 maio 2014.

QUIROGA, R. M. Indicadores de sostenibilidade ambiental y de desarollo sostenible: estado del arte y perspectivas. Santiago do Chile: Naciones Unidas, 2001.

RODRÍGUEZ, R. L.; IGLESIAS, J. L. T.; ÁLVAREZ, N. L. Impacto ambiental en centros da USC. Vicerreitoría de Calidade e Planificación. 2008. 52p. Disponível em: <http://www.usc.es/plands/seccions/datos_plan/eixe2/ pegada_ecoloxica/estudo/estudo_pdf/impacto\%20ambiental\%20final\%20 web-6-6-08.pdf>. Acesso em: 3 out. 2014.

SEBASTIÃO, I. L. C. Aplicação da Pegada Ecológica ao turismo: como a Pegada Ecológica pode influenciar a gestão ambiental. 2010. Dissertação (Mestrado em Gestão e Políticas Ambientais) - Universidade Nova de Lisboa, Lisboa, 2010. Disponível em: <https://run.unl.pt/bitstream/10362/4988/1/ Sebastiao_2010.pdf >. Acesso em: 15 out. 2015.

TURNER, K.; LENZEN, M.; WIEDMANN, T.; BARRETT, J. Examining the global environmental impact of regional consumption activities - Part 1: A technical note on combining input-output and ecological footprint analysis. Ecological Economics, v. 62, n. 1, p. 37-44, abr. 2007. Disponível em: <http:// ac.els-cdn.com/S0921800906005933/1-s2.0-S0921800906005933-main. pdf?_tid=806491b6-8e61-11e6-9bd1-00000aab0f6b\&acdnat=1476046189_ ded9be4771d10718557b012ba4f9c3ea>. Acesso em: 23 maio 2014.

UNIVERSIDADE ESTADUAL PAULISTA “JÚLIO DE MESQUITA FILHO” (UNESP). Anuário Estatístico, 2015. Disponível em: <https://ape.unesp.br/anuario/ pdf/Anuario2015_NOVO.pdf>. Acesso em: maio 2016.

. Campus de Tupã. Plano Anual de Atividades, 2012. Disponível em: <http://www.tupa.unesp.br/Home/ConselhoDiretor/plano_de_ atividades_2012.pdf>. Acesso em: 7 ago. 2014.

WACKERNAGEL, M.; REES, W. Our ecological footprint: reducing human impact on the Earth. 9. ed. Canadá: New Society Publishers, 1996. 
WORLD WILDLIFE FUND (WWF). Pegada Ecológica: que marcas queremos deixar no planeta. 2007. Disponível em: <http://assets.wwfbr.panda.org/ downloads/19mai08_wwf_pegada.pdf>. Acesso em: maio 2014. 